\title{
WHAT MATHEMATICAL EQUIPMENT SHOULD A HIGH SCHOOL GRADUATE HAVE?
}

\author{
By Fiske Allen,
}

Manual Training High School, Indianapolis, Ind.

Not long since, in passing a certain corner, I brushed against two old men whose sound sense was more in evidence than their skill in English; for, as I passed, one was saying to the other, "If things wuzent just as they is"-_."But," interrupted the other, "The facts is, they be." In discussing the question, "What Mathematical Equipment Should a High School Graduate Have?" I wish to consider it from the standpoint, "If things wuzent just as they is," and then consider that "the facts is, they be."

There is, more or less clearly defined in all our minds an outline of the mathematical equipment the high school teacher is trying to give the high school pupil in algebra and geometry. It may be briefly stated as follows: In algebra (I) a clear idea of general number and the laws of the fundamental operations; (2) drill with a large number of particular problems so that he may acquire skill in discovering the general law in the particular problem; (3) skill in handling the equation as a means of discovering the particular numbers satisfying certain conditions; (4) the habit of accuracy in all his mathematical thinking. In geometry we aim at (I) an appreciation of the rigorous logic of the subject; (2) a knowledge of the truths of elementary geometry. In general equipment we are trying to give him (I) a working knowledge of mathematical proof; (2) an appreciation of the beauty of mathematical reasoning; (3) an enthusiasm for intellectual conquest aroused by the subject.

Having stated thus briefly the things some of the less ambitious of us aim to teach our pupils, may we turn to things "as they be," and question, Does the average high school graduate have any complete idea of general number, or is $a$, deep down in the remote convolution, a letter, and 3 a number? Try him. He will add $3^{x}$ and $5 x$ glibly because $3 x^{\prime} s$ and $5 x^{\prime} s$ are $8 x^{\prime}$ 's but ask him to add $a x$ and $a y$ and if he doesn't tell you it can't be done, he will tell you it is $a x+a y$ and then perhaps talk about removing the

\footnotetext{
*Read before the Mathematics section of the Iudiana State Teachers' Association, Dec. 27. 1906.
} 
monominal factor $a$. And this is hardly to be wondered at, when most of our authors of algebra texts define like terms by telling how they are different.

The average graduate does know how to solve particular problems involving the fundamental operations with reasonable accuracy, if caught soon enough after finishing his high school mathematics. But in most high schools no mathematics is required during the fourth year, and the mechanical knowledge of mathematics rusts before it is put to serious use in college or life. In my opinion, a considerable minority of our graduates possess nearly the modest equipment in algebra which we try to give them. The majority have learned algebra as a mass of facts and rules more or less closely related, and so frequently less as to create that disgust for the subject which we would feel toward a study of the dictionary.

In geometry the results are better, for the logic of the subject is so rigorous that both teacher and pupil must realize when the pupil is mastering it. On this account the enthusiasm for the subject on the part of some pupils and the disgust on the part of others is most marked. In general the high school graduate whe has not been given his credit through the sympathy of his teacher, has a fair grasp of the method of geometrical reasoning and some knowledge of the facts of elementary geometry.

In general equipment then, our graduates have a working knowledge of the methods of mathematical proof used in geometry. In algebra he is not so fortunate, for very few schools attempt to prove the laws of the algebraic operations, and few pupils even see the applications of those laws in the particular problems taught. It is to me an interesting fact that more pupils heartily dislike geometry than algebra, though more really master geometry than algebra. A pupil enjoys intellectual conquest. The operations of algebra can be learned and performed correctly without complete knowledge of the reasons, so the pupil can deceive himself into thinking that he knows algebra and enjoy a sense of victory. In geometry no such deceit is possible. The pupil either masters the logic of the subject and enjoys it, or fails to master it, attempts to commit proofs, is not permitted to do so, and becomes disgusted.

If, then, the high school teacher of mathematics can give his pupils a knowledge of the operations and truths of elementary algebra and geometry, a grasp of the methods of reasoning by 
which these truths are reached, and skill in applying them, he has done his full duty toward giving an equipment of mathematical knowledge. If, in addition to these, he has created in them an enthtusiasm for mathematical conquest, an appreciation of the beauty of mathematical proofs, he has given a complete equipment in high school mathematics. I do not believe it is in his province to connect their high school mathematics with physics or the college mathematics. There seems to be too much of a tendency to pull the higher work down to the level of the pupil instead of training them in the lower till they are ready for the higher. The grammar school teacher is attempting high school algebra and must necessarily make arithmetic of it. We have heard it suggested that the elements of analytical geometry and calculus can be introduced into high school algebra. This seems to me a mistake. We should teach our pupils to solve a quadratic equation, but if it is buried in sines, cosines, and infinitesimals, it should be the duty of the college teacher to show the connection between his past knowledge and the new fact.

In conclusion I would say that the high school fails to give the mathematical equipment it aims at for the same reason that the grammar school and the college fail-the immaturity of the pupil. $\mathrm{He}$ is forced to attempt the difficult reasoning of arithmetical analysis when he should be remembering the multiplication table and Latin conjugations. We attempt to thrust upon him ideas of general number and its laws when he is just about ready to enjoy arithmetic. And the college teacher, who, in the nature of the case, cannot continue our mistake, must do again for those whose disgust for the work has not driven them from the subject, the work we could as well have done if we had had the pup:l at the age at which he reaches them. 